\title{
Leptomeningeal metastases in pineoblastoma
}

\author{
Sonia Sandip, ${ }^{1}$ Chandan J Das, ${ }^{2}$ Rohit Kumar Khandelwal ${ }^{3}$
}

${ }^{1}$ All India Institute of Medical Sciences, New Delhi, India ${ }^{2}$ Department of Radiodiagnosis, All India Institute of Medical Sciences, New Delhi, India

${ }^{3}$ Department of Radiology, All India Medical Sciences, New Delhi, India

\section{Correspondence to} Dr Chandan J Das, dascj@yahoo.com

Accepted 6 June 2015

\section{(a) CrossMark}

To cite: Sandip S, Das CJ, Khandelwal RK. BMJ Case Rep Published online:

[please include Day Month Year] doi:10.1136/bcr-2015210343

\section{DESCRIPTION}

Pineoblastoma is one of the pineal parenchymal tumours, which are rare tumours and account for approximately $15 \%$ of all tumours found in the pineal region. ${ }^{1}$ They are malignant tumours that infiltrate the adjacent structures by direct invasion and tend to spread through cerebrospinal fluid (CSF) circulation. ${ }^{2}$ MRI helps in depicting the local infiltration and leptomeningeal spread of the disease. Tumour spread occurs as a result of CSF seeding from direct extension of the tumour through the pia or ependymal lining.

We present an MRI of a 2-year-old boy, a biopsyproven case of pineoblastoma, which revealed a large lobulated mass in the pineal region. It was iso to hypointense on T1-weighted images (T1WIs) (figure 1A) and heterogeneously hyperintense on T2-weighted images (figure 1B). It showed restricted diffusion, seen as hyperintensity on diffusion-weighted image (figure 1C) and hypointensity on corresponding apparent diffusion coefficient image (figure 1D). It showed heterogeneous enhancement on post-gadolinium T1WIs (figure 1E). It was infiltrating the tectum, cerebral aqueduct and third ventricle, and also extending into the fourth ventricle. Secondary obstructive hydrocephalus was present (figure 2A). Leptomeningeal spread was seen as extensive areas of nodular enhancement on contrast images along the sulcal spaces in the cerebral hemispheres, bilateral sylvian fissures, suprasellar cisterns, cerebellar folia, perimesencephalic cisterns and ventricular wall (figure $2 \mathrm{~B}$ and $\mathrm{C}$ ). There were also extensive leptomeningeal metastases along the entire spinal cord, which were seen as nodular enhancement along the spinal cord (figure 2D).

The patient received radiotherapy and is doing well at 3 months of follow-up.

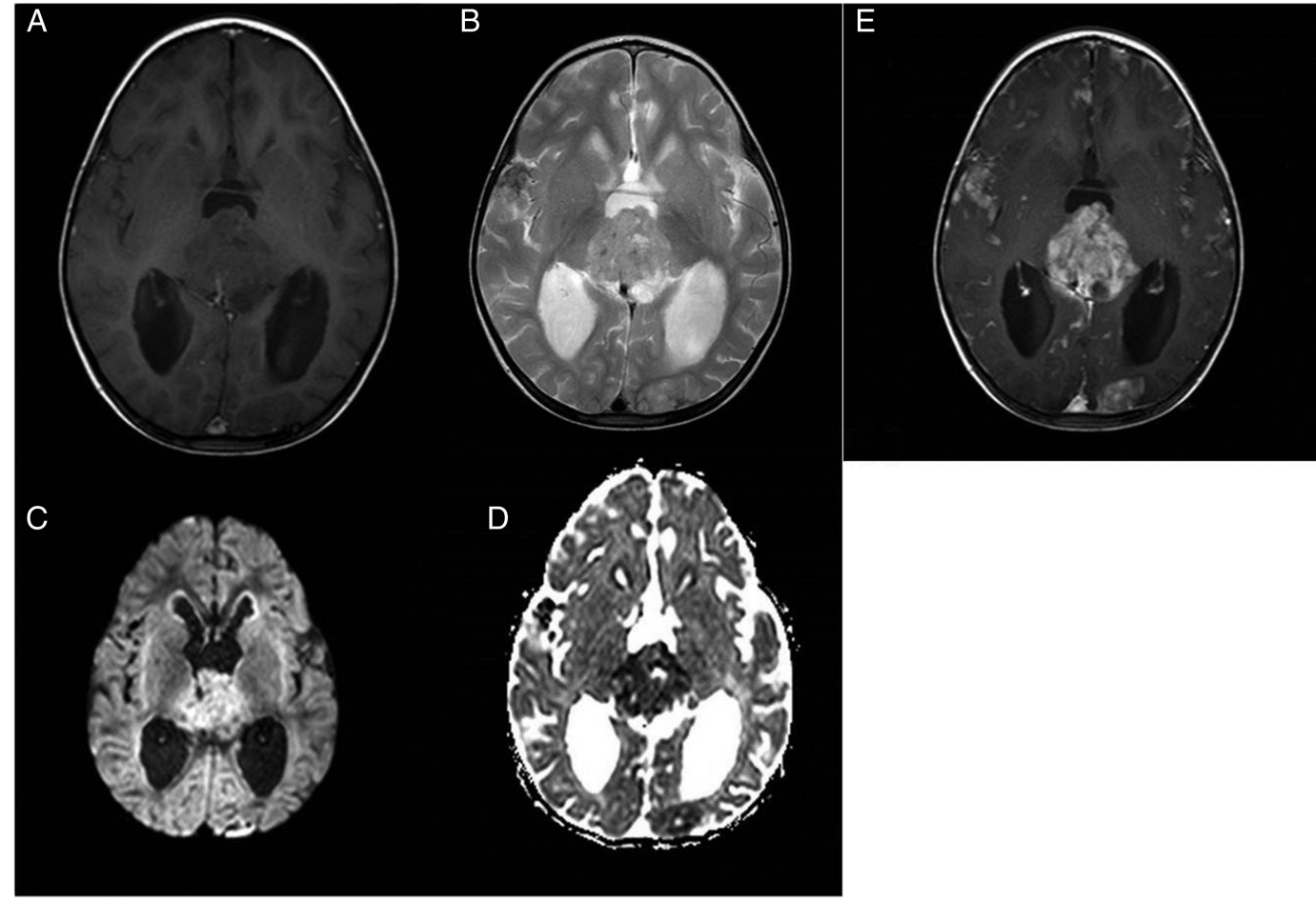

Figure 1 MRI showing a large lobulated mass in the pineal region. (A) Axial T1-weighted image (T1WI) MRI shows isointense to hypointense mass. (B) Axial T2-weighted image shows heterogeneously hyperintensity in the mass. Diffusion-weighted image and apparent diffusion coefficient images reveal restricted diffusion (C and D).

(E) Post-gadolinium axial T1WI showing heterogeneous enhancement. 
Figure 2 (A) Axial fluid-attenuated inversion recovery image showing hydrocephalus and nodularity along the wall of ventricles (white arrow). Post-gadolinium axial and sagittal T1-weighted images (T1Wls) reveal extensive areas of nodular enhancement along the sulcal spaces and cisterns (white arrows) (B and C). (D) Post-gadolinium sagittal T1WI of cervical spine shows nodular enhancement along the spinal cord.
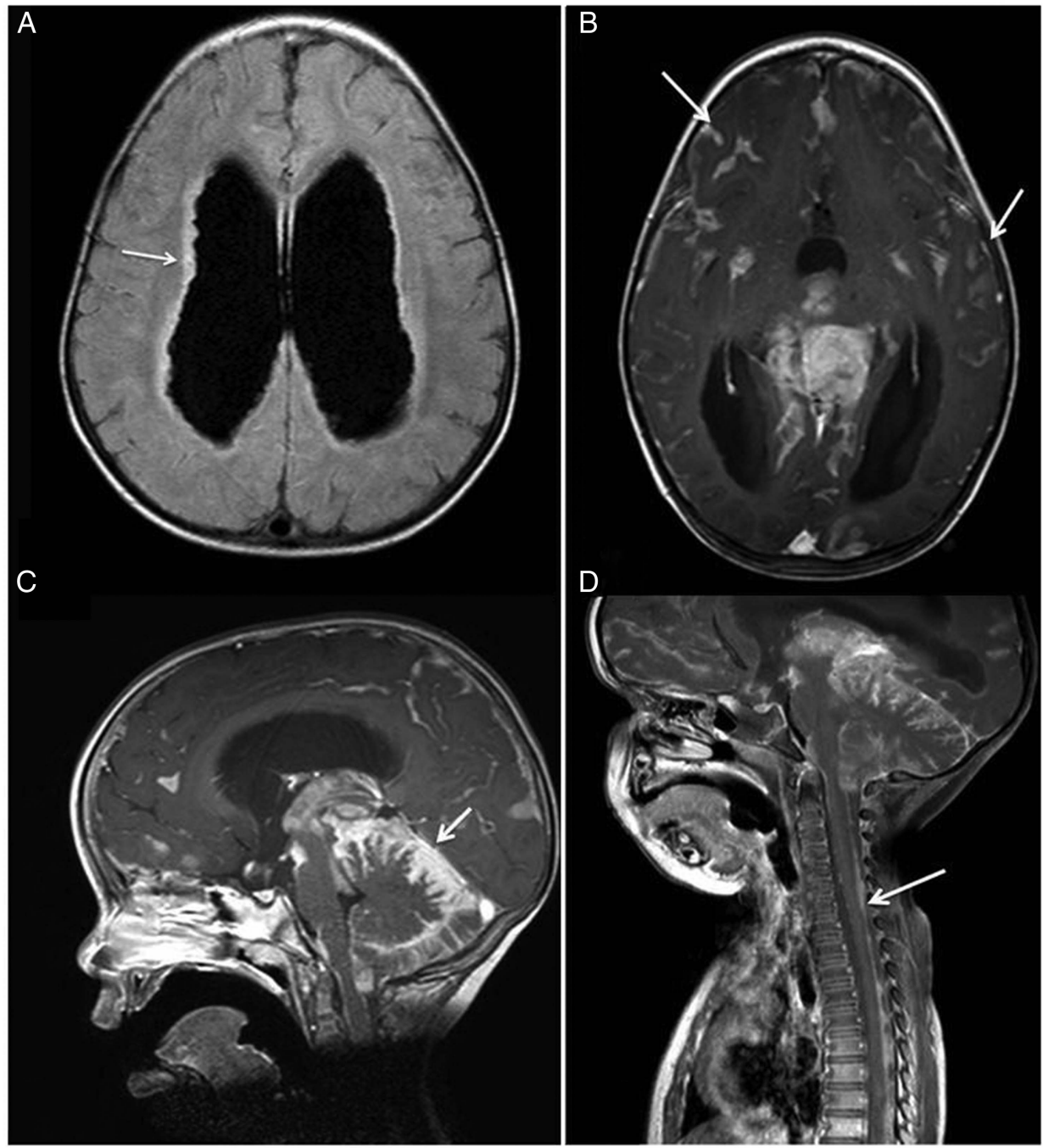

\section{Learning points}

- Although diagnosis of leptomeningeal metastases of tumour is performed by positive cerebrospinal fluid (CSF) analysis, positive cytological findings are seen in only $15-60 \%$ cases of leptomeningeal metastases. ${ }^{3}$

- Hence, a negative CSF analysis does not exclude the possibility of leptomeningeal spread of disease against a background of strong clinical suspicion.

- Gadolinium diethyle netriamine penta acetic contrastenhanced MRI has a high detection rate for leptomeningeal metastases compared to non-contrast MRI.
Competing interests None declared.

Patient consent Obtained.

Provenance and peer review Not commissioned; externally peer reviewed.

\section{REFERENCES}

1 Gasparetto EL, Cruz LCH Jr, Doring TM, et al. Diffusion-weighted MR images and pineoblastoma: diagnosis and follow-up. Arq Neuropsiquiatr 2008; 66:64-8.

2 Reis F, Faria AV, Zanardi VA, et al. Neuroimaging in pineal tumors. J Neuroimaging 2006;16:52-8

3 North C, Segall HD, Stanley $P$, et al. Early CT detection of intracranial seeding from medulloblastoma. AJNR Am J Neuroradiol 1985:6:11-13. 
Copyright 2015 BMJ Publishing Group. All rights reserved. For permission to reuse any of this content visit http://group.bmj.com/group/rights-licensing/permissions.

BMJ Case Report Fellows may re-use this article for personal use and teaching without any further permission.

Become a Fellow of BMJ Case Reports today and you can:

- Submit as many cases as you like

- Enjoy fast sympathetic peer review and rapid publication of accepted articles

- Access all the published articles

- Re-use any of the published material for personal use and teaching without further permission

For information on Institutional Fellowships contact consortiasales@bmjgroup.com

Visit casereports.bmj.com for more articles like this and to become a Fellow 